\title{
The explanatory power of the Delone \& McLean model in the public sector: A mixed method test
}

\begin{abstract}
In Information System research the specific domain of e-government seems to remain underexposed, despite the fact that digital inter-organisational information sharing in the public sector remains a problematic area. Understanding success and failure is one thing that needs to be done to evaluate the effectiveness of public sector information system projects. A highly popular model to conduct such evaluation in the private sector is Delone \& McLean's Information System Success Model. Our research applies this model to three public sector cases in Flanders to verify its explanatory power for the public sector via a questionnaire and interviews. The quantitative results show that most hypotheses of the Delone \& McLean model are valid and applicable to the public sector but do not get the whole picture. Qualitative results reveal that this model ignores the important influence of context factors on IS success/failure.
\end{abstract}

Keywords. Delone \& Mclean, IS success, IS failure, public sector context

\section{Introduction}

Information sharing through inter-organisational information systems (IS) in the public sector holds the potential of more integrated services, richer information, faster problem identification, fraud detection and savings etc. $[14,20]$. Whether this potential is realised depends on several dimensions such as the quality and use of an IS as well as users' satisfaction. Digital inter-organisational information sharing in the public sector remains elusive: little is known about when and how efforts for reaching its potential are likely to be successful [6].

Understanding success and failure is one thing that needs to be done to evaluate the effectiveness of inter-organisational IS projects [15]. Failure and success are tricky but well-known words in the IS field, they are hard to define but extensively researched. What is deemed a success or failure depends even on personal perception $[14,38]$. While there is a wealth of studies on the success/failure of ISs in the private sector, very few studies focus on a public sector setting [35]. It appears that IS researchers show a less than enthusiastic interest hereof [24]. Most of the literature comes from research in the private sector but government IS initiatives are at least similarly complex [18].

In search for IS success or to prevent failure, nearly as much measures as studies were developed over the years. Yet a major breakthrough for the IS research field was Delone \& McLeans' (D\&M) study, which classifies the multiple measures in one IS success model with six main dimensions [15]. This comprehensive model is commonly known as the D\&M model $[9,10]$. Delone \&McLean focus on use as well as experienced benefits and aim to explain IS success/failure. Their model is by far the most common used and cited IS success model [4]. The D\&M model is not used much in public sector studies yet and especially not for inter-organisational ISs $[1,12,31]$.

This article focuses on the explanatory power of the D\&M model for the success/failure of three interorganisational ISs in Flanders. Flanders is the most northern region of the country Belgium. The Flemish government is responsible for the Flemish region as well as the five provinces and 308 municipalities within this region. (1) The first IS under scope is called Going Out, a cultural event database of the Flemish government that is fed by more than 18.000 organisations such as municipalities, Flemish agencies, cultural and leisure organisations. (2) The second IS under study is the Library Information \& Monitoring System (LIMS). Through this system municipal civil servants 
are obliged to annually provide the Flemish government lots of operational information about their library (e.g. number of loans, cultural activities, personnel etc.). (3) Finally, Plan Merits, the third IS, contains spatial data concerning changes in land destination. This information system is used to tax landowners who benefit from a plan merit. The 308 Flemish municipalities are obliged to import data about spatial planning changes in the Plan Merit system of the Flemish government. The three ISs under scope have differing reputations: Plan Merits has in general a poor reputation, LIMS is named nor shamed, while Going Out won the e-government award for usability in 2013 [2].

The explanatory power of the D\&M model is firstly tested via a questionnaire. The quantitative questionnaire results are supplemented by qualitative findings from interviews. Despite several calls, there is still a lack of mixed methods in IS research. The purpose of a mixed method strategy in this paper is twofold: on the one hand adding qualitative data to quantitative data might provide a fuller understanding of IS success/failure [36], and on the other hand additional elements for explaining IS success/failure might surface, which are not covered by the D\&M IS model. This methodology allows to go beyond the main limitation of the D\&M model: i.e. ignoring the context of IS projects [3,34]. As such our research questions are:

a) What is the explanatory power of the D\&M model for the degree of success/failure of three interorganisational information systems in the Flemish public sector?

b) Can a qualitative analysis reveal additional elements contributing to the success/failure of these three ISs which the D\&M model does not cover?

The remainder of the paper is structured as follows. Section 2 introduces the research model and hypotheses. The research design and method are presented in section 3, while we elaborate on the quantitative and qualitative research findings in section 4 and 5. This is followed by a discussion of the research results (section 6) and the main conclusions (section 7).

\section{Research models and hypotheses}

In their literature review Delone \& McLean [10] identify over 100 measures used in more than 180 studies. In a comprehensive attempt to introduce order, Delone \& McLean synthesised a six factor taxonomy from the diversity of IS success dimensions in the studies they reviewed [30]. Ten years after the publication of their first model and based on the evaluation of numerous contributions to it, Delone \& McLean [9] updated their model [12]. The updated model sees success/failure as brought about by causally linked factors: the presence or absence of system, information and service quality influences the intention to use an IS, the actual use and the user satisfaction. These dimensions in turn influence the experienced net benefits. The presence/ absence of net benefits for users impacts the further intention to use and user satisfaction. Finally user satisfaction influences the intention to use while use influences user satisfaction. These potential influences between the factors are described in 12 hypotheses $(\mathrm{H})$ which are pictured in figure 1 . Many previous studies of the D\&M model only did partial tests on these hypotheses [17]. In contrast, this paper follows Petter et al's [27] call to test the complete model. 


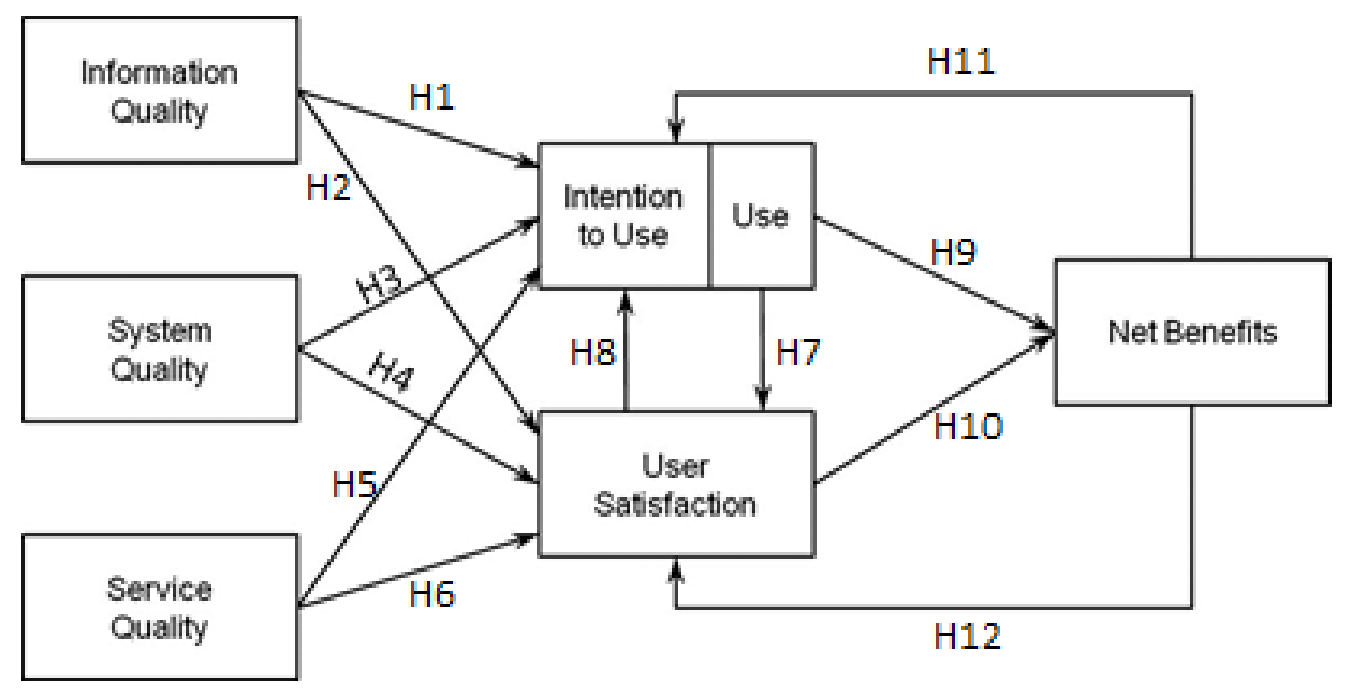

Figure 1 the D\&M model (Delone \& McLean, 2003)

As many subdimensions exist to measure the dimensions of the D\&M model, a selection was made regarding the questionnaire construction. Subdimensions were adopted from relevant previous studies to ensure content validity and in order to answer to Delone \& McLeans's [9] call to utilise the same measures (see appendix table 1). Beside the work of the original authors, the measures were based on studies that applied (parts of the) D\&M model on public sector ISs $[1,15,19,22,29,31-33,35,37,41]$. Each dimension and its main subdimensions are explained in the next paragraphs.

'Information quality' (IQ) focuses on the desirable characteristics of system outputs $[9,10]$. It is measured via completeness, sufficiency and accuracy. Completeness means that all appropriate data items are collected and stored. While sufficiency looks at how adequate the IS is acquiring data of sufficient currency to meet users' informational needs. Finally accuracy means that correct data values are recorded. Users should be assured that there are no errors in the data nor in the IS's output [25].

'System quality' (SQ) measures the quality of information processing within the system. It looks at desirable characteristics of an IS e.g. ease of learning, ease of use, performance and security $[9,10]$. Ease of learning refers to how intuitive an IS is. Ease of use is the degree to which a system is user friendly [11]. Performance is an overall measure created to bundle system quality measures such as response time, system reliability and convenience of access $[23,28]$. The last measure of SQ is security which focuses on the protection of data (models) against unauthorised access.

'Service quality' (SV) looks at the quality of the system support which users receive from the IS project organisation $[9,10]$. It is measured through three items namely reliability, empathy and followup services. Reliability reflects the ability to perform the promised service accurately. While empathy measures the personal attention and caring provided by the staff that manages an IS [26]. Follow-up services include that the staff who manages an IS, keeps itself informed about the course of the IS and its users [32].

'Intention to use' (ITU) measures the user's attitude, while 'use' (U) itself is seen as a behaviour i.e. the manner in which staff and customers use the capabilities of an IS. DeLone and McLean [9] 
contend that 'use' and 'intention to use' can be applied alternately, depending on whether the context involves mandatory or voluntary usage $[33,41]$.

'User satisfaction' (US) is about the extent to which users believe that the available IS meets its information requirements [23]. It is measured via personal satisfaction, effectiveness and word-ofmouth communication. Personal satisfaction is the sum of one's feelings or attitudes towards a variety of dimensions affecting the situation [30]. Effectiveness is the capability of an IS to produce a result desired by the user [35]. Word of mouth communication is the degree to which a user would recommend an IS.

'Net benefits' (NB) are the extent to which an IS contributes to the success of individuals that use the system or to their underlying organisation. It is an important facet of the overall value of the system [28]. Net benefits can be measured via task compatibility, job impact and net value for the organisation. Task compatibility is the fit or consistency between the task and the IS that supports the task [27]. Job impact looks at the effect of an IS on a user's job execution and process of working, it is the most common measure of net benefits at the individual level. The net value for an organisation is mapped in order to measure net benefits at organisational level [28]. Table 2 of the appendix contains an overview of the questions per (sub)dimension.

\section{Research design and method}

The research design consist of two main steps namely a questionnaire and interviews. Firstly, in order to research the explanatory power of the D\&M model for measuring the degree of success/failure, a questionnaire was chosen as an appropriate research method [7,31]. Data were collected via a selfadministered questionnaire. A questionnaire allows to collect data from respondents in a relatively short and specific period of time, in this case in the month April 2015 [16].

To increase the generalisability of the results and in order to compare potential differences, the respondents were spread across three ISs in Flanders selected from an inventory of inter-organisational 1Ss in Flanders [39]: Going Out, the Library Information \& Monitoring System and Plan Merits. These three ISs differ in reputation, and have been operational for several years.

The sample of the study covers a range of respondents from different municipalities, inter-municipal, provincial, Flemish and private organisations. Initially a preliminary version of the questionnaire was pretested to verify the comprehensiveness and appropriateness. These respondents were 6 IS users, 3 Flemish managers of the 3 IS projects as well as 4 researchers. Some small refinements were made based on their feedback. The Flemish managers of the three ISs provided a contact list of respondents. For LIMS and Plan Merits the number of respondents covered the total population (respectively 314 and 501), for Going Out an at random selection was made (4000 of the 18.000 potential users). A total of 4815 questionnaires were distributed via an online survey programme, the potential respondents received a personal invitation email with a personal link. The respondents received an adapted questionnaire depending on whether they used, stopped using or never used the IS in question. Participation to the survey was voluntary, and two reminders were send. In total 1593 completed survey questionnaires were gathered which represent a response rate of $33 \%$. More specifically we obtained 1247 on 4000 respondents (31,2\%) for Going Out, 217 on 501 (43,3\%) for Plan Merits and 129 on $314(41,1 \%)$ for LIMS. 156 surveys were incomplete and left out. 
The following step in our research design was interviewing users of the ISs. Users who did and did not answer the questionnaire were asked about their experience and whether they agreed with the survey results. Interviews are an interesting addition to the questionnaire for three reasons. Firstly, because interview data help to better grasp the (public) context of the three ISs. Secondly, a check for potentially additional elements of success/failure can be done. Thirdly, the qualitative data can explain complex or contradictory survey results [13]. Mixing survey data with interviews is a profound form of triangulation, one type of the data provides a broader view, while the other gives greater depth. Together they should yield results from which one can make more accurate inferences [36].

The respondents were offered the choice between a telephone or face-to-face interview. Consequently, 52 telephone interviews of 10 to 15 minutes and 2 face-to-face interviews of one hour were conducted for Plan Merits. Four face-to-face group interviews with in total 40 participants were organised for LIMS, which lasted between 30 minutes and an hour. Finally, 51 telephone interviews were done for Going out, lasting on average 10 to 15 minutes.

\section{Quantitative research findings}

A factor analysis was conducted to test whether the subdimensions of each dimension of the D\&M model form a valid scale. The analysis confirmed that the subdimensions of information (IQ), system (SQ) and service quality (SV) as well as net benefits (NB) form a valid scale. Based on its validity and reliability scores it seems better to leave 'expectations' out of the scale construction for user satisfaction (US). Only personal satisfaction and recommendations are taken into account, as these form a reliable scale for user satisfaction. The dimension (intention to) use is not measured by subdimensions. A reliability analysis via Cronbach's alpha was also conducted to provide an indication of the internal consistency of the subdimensions for measuring the same dimension. The dimensions IQ $(0,714)$, SQ $(0,748)$ and NB $(0,824)$ proved to be reliable scales. SV scored with 0,682 just below the preconceived threshold of 0,700 which is defendable [21]. The score for US confirms that it is better to leave expectations out. Table 3 in the appendix presents the mean, standard deviation, scale, number of respondents and missing values for the six dimensions of the D\&M model and their subdimensions. The highest overall standard deviation of the SV subdimension 'follow-up service' indicates that respondents are largely scattered in their opinion about the degree to which the Flemish government installs a follow-up service.

A bivariate analysis shows that the three quality dimensions of the D\&M model are clearly correlated. The bivariate interrelation between IQ and SQ is the strongest, according to a Pearson's correlation coefficient of 0,492. Yet the correlation of SQ-SV and IQ-SV are medium (both 0.411). Based on a Principal Component Analysis of the ten subdimensions of IQ, SQ and SV, the division of the D\&M model in three separate quality dimensions is validated (see appendix table 4). For US the bivariate Pearson's correlation coefficient points to a medium correlation between US and SQ (0.550). Yet the correlation of US with IQ and SV is also medium $(0,459$ and 0,452$)$. Finally, based on a bivariate Pearson's correlation coefficient of 0.642 points, NB are strongly correlated with US.

Table 5 shows support the following hypotheses (H): H2 (IQ -> US), H4 (SQ -> US), H6 (SV-> US) $\&$ H7 (U-> US), H10 (US -> NB) and H12 (NB -> US). No support was found for hypotheses 9 (U$>\mathrm{NB}$ due to a $\mathrm{R}^{2}$ of $0,1 \%$ and p-value of 0,330 ). While the five remaining hypotheses could be supported: H1 (IQ -> ITU), H3 (SQ -> ITU), H5 (SV -> ITU), H8 (US -> ITU) and H11 (NB -> ITU). The p-values are nearly all below 0,001 and as such the hypotheses appear to be very significant. The $\mathrm{p}$-value for the relation between use and user satisfaction is smaller than 0,005 . As some researchers 
interchangeably apply use and intention to use, we checked the relation of intention to use and user satisfaction: It appears to be more significant (ITU->US, $\beta=0,295, p<0,001$ ). If we do the same for intention to use and net benefits, no support was found as was the case for use (ITU->NB, $\beta=0,076$, $\mathrm{p}=0,071$ ). In short the validation of the $\mathrm{D} \& \mathrm{M}$ model using questionnaire data of three e-government ISs indicates that all relationships are supported, except the relation between use and net benefits.

The survey measured several background characteristics linked to the dimensions of the D\&M model. First, the 'type of IS' (i.e. Going Out, LIMS or Plan Merits) leads to considerable differences. Users of Plan Merits are the least satisfied about the three quality dimensions. Going Out scores the highest on IQ and SV, 'LIMS' on SQ. Users of Going Out show the highest satisfaction $(7,1 / 10)$, users of LIMS are slightly less satisfied (6,45/10), while the satisfaction level of Plan Merits drops under the neutral midpoint to 4,46/10. The highest NB scores are for Going Out while LIMS scores a bit lower. Yet the low scores of Plan Merits catch most attention. The future ITU for Going Out is higher than for LIMS and much higher than for Plan Merits (60,8\% vs $47,3 \%$ vs 6,5\%). The 'type of IS' explains between $2,4 \%$ (IQ) and $13,3 \%$ (NB) of variance. A second characteristic 'experience' has an influence: respondents who do not use the system any more are in general less satisfied than current users and notice fewer net benefits. They also show a considerably lower future intention $(56,4 \%)$ than current users $(83,9 \%)$. The same counts for those who possess an own alternative IS and have to transfer data from their own IS to one of the three ISs under study. A third characteristic 'gender' plays a role for IQ, SQ and use: men are slightly more satisfied about IQ and the subdimension 'performance'. Women are more satisfied about the subdimenions 'ease of use' and 'learning'. They use the ISs more than their male counterparts $(76,7 \%$ versus $66,2 \%)$ and show a higher future intention to use $(55 \%$ vs $49,7 \%)$. Venkatesh et al [40] confirm that gender plays a role on the perception of an IS. A fourth characteristic 'age' has an influence too, the older the respondent, the lower one's satisfaction of SQ and SV. On the other hand, the youngest and oldest respondents seem to use the studied ISs the most. A possible explanation is that younger people are digital natives [40], while older people might have more experience. Specifically for Going Out interviewees mentioned that mainly retired volunteers conduct data entries. Finally 'type of organisation' plays a role as well: private sector respondents are considerably more motivated than public sector respondents. Regression analysis is a statistical process for estimating the relationships among variables. The explanatory value of all background variables without 'type of IS', varies between 3,7\% for SQ to $6,8 \%$ for NB. Yet their explanatory value is ruled out when taking into account the components of the D\&M model. US and SV are the dominant variables.

In a regression model with the three D\&M quality dimensions as independent variables and US as dependent, we see that together IQ, SQ and SV explain 39,5\% variance of US. All three are important but SQ is the most decisive (see table 6). If ITU is added to the three quality dimensions, the explanatory value rises up to $47,7 \%$. These high scores were not influenced by multicollinearity. If net benefits are explained by the three quality dimensions, ITU and US, 40,3\% of variance could be explained $(\mathrm{N}=424)$. Only two variables appear to be significant: service quality and user satisfaction. The latter is the most paramount, which was already clear from the strong bivariate correlation $(\mathrm{R}=$ 0,642). Nevertheless, adding service quality contributes significantly to a better model. US and SV are the only two variables which are withheld when applying a forward-procedure. Finally if a net benefit regression analysis of all $\mathrm{D} \& \mathrm{M}$ dimensions and the background characteristics is conducted in one model, $41,1 \%$ variance could be explained $(\mathrm{N}=419)$. As such, compared to the previous regression model $(40,3 \%)$, the background characteristics do not have much additional explanatory power. US and SV stay dominant. 


\section{Qualitative research findings}

Adding qualitative data to the survey results provides a fuller understanding of the success/failure of the three studied ISs. The interviews also allowed the detection of additional elements which explain the ISs' success/failure and which the D\&M model does not cover:

While Going Out receives a high information quality score, qualitative data analysis reveals some points of improvement (e.g. no automatic removal of outdated events and too narrow data categories). LIMS also scores high on IQ because the Flemish IS project organisation guarantees a certain level of IQ by controlling municipalities. Finally, the IQ of Plan Merits suffers of incomplete data. The interviews revealed four factors which influence IQ that are not covered by the D\&M. (1) Cultural barriers: for LIMS no entries were made for data fields on e.g. dyslexia or religion of book loaners because local civil servants experienced these as too private to ask about. (2) Inter-governmental relationships also influence IQ. The data categories in LIMS are too broad which led to semantic interoperability problems, some regional library associations made definition agreements to solve this matter. (3) Organisational capacity influences IQ too: because of their limited capacity, smaller municipalities admitted not entering data in Plan Merits or just 'estimating' some data for LIMS. (4) An intra-organisational factor stimulated larger municipalities to estimate their data too, this happens when the financial department obstructs data import because it does not provide the required data.

For system quality a remarkable contradiction between quantitative and qualitative data surfaced. Although the SQ of Going Out is lower than LIMS, based on the quantitative data there is no reason to expect considerable SQ problems. Yet the large majority of interviewees complains about multiple shortcomings (e.g. system crashes with data loss, an inaccurate search engine, no option to remember data, slow transfer of data corrections and sorting of cultural events on the date of data entry instead the date of the event). This is even more remarkable because the IS won an e-government award for 'usability'. For LIMS interviewees are indeed very satisfied with the SQ. For the third IS, Plan Merits, qualitative results confirm a poorer system quality. The system is not intuitive as it is designed for rural experts. It is also hard to $\log$ in and to convert data to this IS.

The qualitative data confirm that project leaders of Going Out ensure a high service quality. The Flemish project organisation of LIMS also tries to support users, in fact SV is so high that it sometimes complicates the IS. For example, high service quality resulted in the addition of too detailed data category descriptions, causing people to overlook relevant issues. The project organisation of Plan Merits sometimes enters the data for puzzled municipalities, yet it is often understaffed. The IS's error notifications provide a cryptic code, which is hard to interpret. For all three ISs large instructing guides are offered. The interviews reveal that due to context factors extra service quality (e.g. by provinces or inter-municipal joint authorities) is offered, something which the D\&M model does not uncover.

Interviews learn that the respondents tend to use Going Out mainly as a promotion tool to reach a larger audience for their cultural activities. The use of the second IS, LIMS, is mandatory for all municipal libraries. They mainly use the data for benchmarking or to convince their municipal council. The use of Plan Merits is an obligation for municipalities which make spatial implementation plans that imply plan merits. Yet in practice 150 of the 217 respondents of the survey never used this IS. Interviewees confirmed a high degree of non-use: many claim that they just never have been confronted with plan merits. Like for IQ, several factors which are not detected by the D\&M model 
but influence (intention to) use. One overlaps with factor (2) of IQ namely 'inter-organisational relationships': using Going Out is in theory voluntary yet many organizers of cultural events feel obliged to use it as it is only way to get their event published on municipal websites. Municipalities indirectly oblige use of Going Out because they can automatically extract data to their website which is timesaving. On the other hand, the intention to use Plan Merits was impeded by clouded interorganisational relationships between the Flemish and local governments. Two other factors can be added to the list of factors which are not covered by the D\&M model: (5) The availability of alternative ISs: some respondents for Going Out use competing sites to announce their activities. Similarly, a better upcoming alternative IS made that some municipalities did not intend to use Plan Merits. Users of LIMS would like to couple it with another partially overlapping Flemish IS. (6) Political motives: Some have a low intention to use Going out because they fear control by an organisation that ins royalties. Such political motives were also detected for Plan Merits: it forms a high burden for municipalities and local politicians see an opportunity for electoral gains by preventing Flemish plan merit taxes. Because of that the deadline to enter data in the IS was sometimes deliberately not met.

The qualitative analysis confirms that although there is room for improvement, most respondents are satisfied about Going Out, the same counts for LIMS. In contrast, user satisfaction of Plan Merits is low: the IS is very technical and hard to learn and use.

While the respondents of Going Out expect an increased visibility of their events due to the use of this IS, they would like to get a confirmation that this net benefit is indeed achieved. Users of LIMs believe that the availability of a high amount of data is an advantage, as many other municipal departments lack data. Some respondents believe that LIMS is too detailed, fewer details would provide the same benefits. Municipal users of Plan Merits do not experience much net benefits and propose that the Flemish government who enjoys the plan merit tax revenues enters all data.

\section{Discussion}

The first goal of this research was to investigate the explanatory power of the D\&M model for the degree of success/failure of three inter-organisational ISs in the Flemish public sector. It appears that this model indeed can be applied to public sector cases: 11 of its 12 hypotheses appeared to be valid. The findings for hypotheses 1-8 and 10 are in line with those of other public sector IS researchers. ${ }^{1} \mathrm{We}$ did not find public sector articles with research results on $\mathrm{H} 11$ and H12, as most researchers only partially test the D\&M model $[17,28]$. Hypothesis 9 could not be validated, which is in contrast to the findings of Abdelsalam or Wang \& Liao [1,41]. Petter et al [28] remark that the D\&M dimensions are measured using different subdimensions which causes discrepancies in results. The lack of relation between use and net benefits can be explained via the interviews: users of Plan Merits do not experience a benefit in return, and users of Going Out expect the benefit that their cultural events reach a larger audience but are not sure of this. While using LIMS provides some benefits, it is not crucial for the daily operations of libraries. Finally, several background characteristics appeared to have an influence too, although these were ruled out by the dimensions of the D\&M model, which provides an extra confirmation of the model.

\footnotetext{
${ }^{1} \mathrm{H} 1$ [31,35,37], H2 [15,31,35,41], H3 [1,31], H4 [1,31,35,37,41], H5 [1,41 both take U instead of ITU], H6 [15,35,37,41], H7 [1], H8[37], $\mathrm{H} 10[1,35,41]$. Caution in this comparison is necessary, there is little consensus on the appropriate measures of IS Success, which implies that studies are difficult to compare $[17,30]$
} 
Via the D\&M model, the degree of success/failure of the three Flemish ISs can be explained: The first IS, Going Out, scored the highest on all dimensions except for SQ. The positive scores on the three quality dimensions positively influence the ITU and US of Going Out. If there was no obligation, a broad majority of users $(60,8 \%)$ would still use this IS. A user satisfaction of 7,1/10 combined with high usage by $78,2 \%$ of the respondents (which is partly the consequence of a municipal obligation), positively influence experienced net benefits. This positive experience reinforces the subsequent use and user satisfaction. The second IS, LIMS, scored the highest on SQ and the second highest on IQ and SV, which positively influences the ITU and US. The current percentage of usage is $73,6 \%$, but it would drop to $47,3 \%$ if the respondents could freely decide to use the IS. The user satisfaction is on average positive (with a score of $6,45 / 10$ ). In combination with a high usage $(73,6 \%)$, this positively influences net benefits to a satisfying level. The third IS, Plan Merits, scored lowest on the three quality dimensions. This has a rather negative influence on ITU and US. Although municipalities are obliged to use this IS, only $30 \%$ of the respondents actually use it. This number would tumble to $6 \%$ if the use of this IS was voluntary. Combine this with a user satisfaction of 4,46/10 and it becomes no surprise that many municipalities do not experience any net benefits. The lack of net benefits does not encourage future use nor the user satisfaction. According to the D\&M model, Going out is the most successful IS, LIMS scores a bit lower but could still be deemed a success. Nevertheless several points of improvement were detected for both ISs. We consider Plan Merits as an IS failure because it scores low on all dimensions of the D\&M model.

The interview data enrich the quantitative data. The qualitative findings largely run parallel with the quantitative results, yet for the dimension 'system quality' a remarkable contradiction between the two surfaced. A potential explanation is that the literature based survey subdimensions focused on other aspects than some aspects considered by the interviewees. The qualitative data also reveal six influencing context factors that the D\&M model does not cover, a finding that confirms the second research question. Six relevant context elements that influence information quality, service quality and (intention to) use were uncovered: cultural barriers, intergovernmental and inter-organisational relationships, organisational capacity, intra-governmental relationships, the availability of alternative ISs and political motives.

\section{Conclusions}

The conducted research answered the call to test the explanatory power of the D\&M model in a public sector [30]. Via a questionnaire twelve hypotheses were tested on three inter-organisational ISs in the public sector. All hypothesized relationships of the D\&M model were significantly supported, except for the relationship between use and net benefits. The D\&M model appeared to have a certain power to explain the success/failure of these three ISs. An interesting addition to the dimensions of the D\&M model is the study of background characteristics such as kind of IS, age, gender, experience and kind of organisation. These influence respondents' perception of the D\&M dimensions. A main critique on the D\&M model is that it does not take into account the context of IS projects [3]. Based on our research results, we share this view. By adding a qualitative analysis based on interviews to the quantitative questionnaire results, six influencing context elements concerning the degree of success/failure of the ISs were revealed.

The investigation of the D\&M model is relatively new in the public sector and only three ISs were investigated. Caution is necessary when generalising findings. Nevertheless the main contributions of this paper are that it tested the D\&M model as a whole in the public sector $[28 ; 30]$ and showed that the model can be applied to public sector cases. It has some explanatory power concerning the degree 
of IS success/failure. Where not much mixed method IS research is conducted before [36], this paper shows that it has added value as the qualitative results provided a more in-depth explanation of the broad quantitative findings. In general the qualitative and quantitative results ran parallel, yet a discrepancy was found concerning system quality. It would be interesting to elaborate further on this matter in future research. The qualitative analysis also revealed six influencing context elements which the quantitative findings did not. As such doing the same analysis with other public ISs would be a valuable direction for future research.

\section{Acknowledgements}

The authors would like to thank prof. Dr. Marijn Janssen for his valuable input during the preparation of the questionnaire.

\section{References}

1. H. Abdelsalam, C.G. Reddick and H.A. El Kadi, Success and Failure of Local E-Government Projects: Lessons Learned from Egypt, in: S.K. Aikins, Managing E-government Projects. Concepts, Issues and Best Practices, Hershey, Information Science Reference, 2012, pp. 242261.

2. Agoria, Agoria eGov awards. (2013). Available: http://www.agoria.be/nl/Nieuwe-websitevan-Brugge-grote-winnaar-van-Agoria-eGov-Awards

3. K. Axelsson and U. Melin Contextual Factors Influencing Health Information Systems Implementation in Public Sector - Investigating the Explanatory Power of Critical Success Factors, Lecture Notes Computer Science, 8653 (2014), 59-71.

4. F. Bannister and R. Connolly, The Great Theory Hunt: Does e-government really have a problem?, Government Information Quarterly, 31(5) (2015), 1-11.

5. D. Besterfield, C. Besterfield-Michna, G. Besterfield and M. Besterfield-Sacre, Total Quality Management, Pearson Education, Englewood Cliffs, 2011, 484 pgs.

6. B. Chen, Assessing Inter-Organizational Networks for Public Service Delivery A ProcessPerceived Effectiveness Framework, Public Performance \& Management Review, 31(3) (2008), 348-363.

7. J. Choudrie and Y. Dwivedi, Investigating the Research Approaches for Examining Technology Adoption Issues, Journal of Research Practice, 1(1) (2005), 1-12.

8. F.D. Davis, Perceived usefulness, perceived ease of use, and user acceptance of information technology, Management Information System Quarterly, 13(3) (1989), 319-334.

9. W.H. DeLone and E.R. McLean, The DeLone and McLean Model of Information Systems Success: A Ten-Year Update, Journal of Management of Information Systems, 19(4) (2003), 9-30.

10. W.H. DeLone and E.R. McLean, Information Systems Success: The Quest for the Dependent Variable, Information Systems Research, 3(1) (1992), 60-95.

11. W.J. Doll and G. Torkzadeh, The Measurement of End User Satisfaction, Management Information Systems Quarterly, 12(2) (1988), 259-274.

12. S. Dörr, S. Walther and T. Eymann, Information Systems Success - A Quantitative Literature Review and Comparison, 11th International Conference on Wirtschaftsinformatik, Leipzich, 2013, 1813-1827. 
13. Driscoll, D.L., A. Appiah-Yeboah, P. Salib and D.J. Rupert, Merging Qualitative and Quantitative Data in Mixed Methods Research: How To and Why Not, Ecological and Environmental Anthropology, 3(1) (2007), pp. 19-28.

14. Y.K. Dwivedi, D. Wastell, S. Laumer, H. Zinner Henriksen, M.D. Myers, D. Bunker, A. Elbanna, M.N. Ravishankar and S.C. Srivastava, Research on information systems failures and success: status update and future directions, Information System Frontiers, 17(1) (2014), 143-157.

15. J. Floropoulos, Ch. Spathis, D. Halvatzis and M. Tsipouridou, Measuring the success of the Greek Taxation Information System, International Journal of Information Management, 30 (2010), 47-56.

16. F. J. Fowler, Survey research methods. London, SAGE Publications, 2002, 179 pgs.

17. G.G. Gable, D. Sedera and T. Chan. Re-conceptualizing Information System Success: The ISImpact Measurement Model, Journal of the Association for Information Systems, 9(7) (2008), 377-408.

18. R. Gil-Garcia, Enacting Electronic Government Success, New York, Springer, 2012, 272 pgs.

19. J.R. Gil-Garcia, I. Chengalur-Smith and P.D. Duchessi, Collaborative e-Government: impediments and benefits of information-sharing projects in the public sector, European Journal of Information Systems. 16 (2007), 121-133.

20. J.R. Gil-Garcia, S.A. Chun, M. Janssen, Government Information Sharing and Integration: Combining the social and the technical, Information Polity, 14 (2009), 1-10.

21. J.F. Hair, R. E. Anderson, R. L. Tatham and W.C. Black, Multivariate data analysis with readings. New York, Macmillan Publishing Company, 1992, 730 pgs.

22. R. Hussein, N.S.A Karim and M.H. Selamat, The impact of technological factors on IS success in the electronic-government context, Business Process Management Journal, 13(5) (2007), 613-627.

23. B. Ives and M. Olson, User Involvement and MIS Success: A Review of Research. Management Science, 30(5) (1984), 586-603.

24. M.L. Nandi and G.K. Nayak, Information systems management in public sector organizations. In: B.S. Panda \& A. Nayak (Eds.), 29th International Conference on Information Technology, Bhubaneswar, 17-20 December 2008, 289-294.

25. K.E. Newcomer and S.L. Caudle, Evaluating Public Sector Information Systems: More Than Meets the Eye, Public Administration Review, 51(5) (1991), 377-384.

26. A. Parasuraman, V.A. Zeithaml, and L.L. Berry, SERVQUAL: A multiple-item scale for measuring consumer perceptions of service quality, Journal of Retailing, 64(Spring) (1988), $12-40$.

27. S. Petter, W. DeLone and E.R. McLean, Information Systems Success: The Quest for the Independent Variable, Journal of Management Information Systems, 29(4) (2013) , 7-61.

28. S. Petter, W. DeLone and E.R. McLean, Measuring information systems success: models, dimensions, measures and interrelationships, European Journal of Information Systems, 17 (2008), 236-263.

29. V.R. Prybutok, X. Zhang and S.D. Ryan Evaluating leadership, IT quality, and net benefits in an e-government environment, Information and Management, 45 (2008), 143-152.

30. A. Rai, S.S. Lang and R.B. Welker, Assessing the validity of IS Success Models: An empirical test and theoretical analysis, Information Systems Research, 13(1) (2002), 50-69.

31. N.P. Rana, Y.K. Dwivedi and M.D. Williams, Evaluating the Validity of IS Success Models for the Electronic Government Research: An Empirical Test and Integrated Model. International Journal of Electronic Government Research, 9(3) (2013), 1-22. 
32. M. Sambasivan, G.P. Wemyss and R.C. Rose, User acceptance of a G2B system: a case of electronic procurement system in Malaysia Murali, Internet Research, 20(2) (2010). 169-187.

33. M. Scott, W. DeLone and W. Golden, Understanding net benefits: a citizen based perspective on e-government, 30th International Conference on Information Technology, Phoenix, 2009, $1-11$.

34. P.B. Seddon, S. Staples, R. Patnayakoni and M. Bowtell, Dimensions of Information System Success, Communications of the Association for Information Systems, 2(3) (1999).

35. H. Sørum, R. Medaglia, K. Normann Andersen, M. Scott and W.H. DeLone, Perceptions of IS Success in the Public Sector: Webmasters at the Steering Wheel? Transforming Government People, Process and Policy, 6(3) (2012), 239-257.

36. C. Teddlie and A. Tashakkori (2009). Foundations of Mixed Methods Research, Thousand Oaks, Sage Publications, 400 pgs.

37. T. Teo, S.H. Srivastava and L. Jiang, Trust and Electronic Government Success: An Empirical Study, Journal of Management Information Systems, 25(3) (2008), 99-131.

38. N. Urbach, S. Smolnik and G. Riempp, The State of Research on Information Systems Success - A Review of Existing Multidimensional Approaches, Business \& Information Systems Engineering, 1(4) (2009), 315-325.

39. anonymised

40. V. Venkatesh, M.G. Morris, G.B. Davis and F.D. Davis, User acceptance of information technology: towards a unified view. Management Information System Quarterly, 27(3) (2003), 425-478.

41. Y-S. Wang and Y-W. Liao, Assessing e-Government systems success: A validation of the DeLone and McLean model of IS success, Government Information Quarterly, 25 (2008), 717-733. 


\section{Appendix}

Table1 Measures per subdimension based on previous research

\begin{tabular}{|l|l|}
\hline SQ1_Ease of learning & {$[10,27]$} \\
SQ2_Ease of use & {$[1,8,10,11,15,28,29,32,33,35,37,41]$} \\
SQ3_Performance & {$[9,23,27]$} \\
SQ4_Security & {$[9,23,32,35,41]$} \\
IQ1_Completeness & {$[10,27,32,33]$} \\
IQ2_Sufficiency & {$[5]$} \\
IQ3_Accuracy & {$[9,10,15,27,29,32,33,35,37,41]$} \\
SV1_Reliability & {$[9,26,27,29,32]$} \\
SV2_Empathy & {$[9,27,29,33,35]$} \\
SV3_Follow-up services & {$[32]$} \\
ITU & {$[9]$} \\
U & {$[9,10]$} \\
US1_Personal satisfaction & {$[1,37,41]$} \\
US2_Effectiveness & {$[35,41]$} \\
US3_Word-of-mouth communication & {$[27]$} \\
NB1_Task compatibility & {$[27]$} \\
NB2_Job impact & {$[1,28,41]$} \\
NB3_Net value organisation & {$[23,33]$} \\
Age & {$[15,19,22,27,35,40]$} \\
Gender & {$[15,19,22,27,35,40]$} \\
Experience & {$[15,19,35,40]$} \\
Voluntariness of use & {$[40]$} \\
\hline
\end{tabular}

Table 2 Survey question per subdimension ${ }^{1,2}$

\begin{tabular}{|c|c|}
\hline \multicolumn{2}{|l|}{ System quality (SQ) } \\
\hline SQ1_Ease of learning & Learning how to use the system is easy \\
\hline SQ2_Ease of use & The system is easy to use \\
\hline SQ3_Performance & The system is performant (e.g. fast enough, no crashes) \\
\hline SQ4_Security & I am confident that the system is secured against penetration by unauthorized people \\
\hline \multicolumn{2}{|l|}{ Information quality (IQ) } \\
\hline IQ1_Completeness & I enter every data-input as complete as possible \\
\hline IQ2_Sufficiency & The available information in the system is sufficient to fulfil my tasks \\
\hline IQ3_Accuracy & In general the information in the system is up-to-date \\
\hline \multicolumn{2}{|l|}{ Service quality (SV) } \\
\hline SV1_Reliability & $\begin{array}{l}\text { When I experience a problem with the system, the Flemish government has the necessary } \\
\text { competences to solve it }\end{array}$ \\
\hline SV2_Empathy & $\begin{array}{l}\text { I have the feeling that the Flemish government shows sincere interest to understand my specific } \\
\text { needs. }\end{array}$ \\
\hline SV3_Follow-up services & The Flemish government has already informed about my user satisfaction since I use the system \\
\hline \multicolumn{2}{|r|}{ ( } \\
\hline Use & Do you have any experience with the information system? \\
\hline \multicolumn{2}{|l|}{ Intention to use (ITU) } \\
\hline ITU & $\begin{array}{l}\text { OPTION A. Are you planning to use the system in the future? } \\
\text { OPTION B. If the system was not mandatory, would you use it in the future? }\end{array}$ \\
\hline Stimulators & $\begin{array}{l}\text { OPTION A I feel stimulated by a financial reward, the Flemish government/ my administrative } \\
\text { chief/ political superiors/ the usefulness for my job } \\
\text { OPTION B I feel obliged because of a financial reward/ the Flemish government/ my } \\
\text { administrative chief/ political superiors }\end{array}$ \\
\hline \multicolumn{2}{|l|}{ User satisfaction (US) } \\
\hline US1_Personal satisfaction & In general I am satisfied with the system \\
\hline US2_Effectiveness & The system meets my expectations \\
\hline
\end{tabular}


US3_Word-of-mouth Would you recommend the system?

communication

Net benefits (NB)

NB1_Task compatibility The system is an essential element to fulfil my tasks

NB2_Job impact The system makes my job easier

NB3_Net value org. I clearly see the added value of the system for my organisation

Moderating factors (MF)

A_Age Mark in which age category you are situated

G_Gender What is your gender?

E_Experience How long are you already busy with library info/spatial planning/culture ${ }^{3}$ for your job?

V_Voluntariness of use Are you in any way obliged to enter data into the system?

Other: organisation I work for... (prefilled and open option)

Other: inhabitants per How much inhabitants counts your employing municipality approximately?

municipality

${ }^{1}$ Translated from Dutch

${ }^{2}$ If respondents did not use the system anymore, the same questions were asked in the past tense.

${ }^{3}$ Option differs along the IS under question

Table 3 Descriptive statistics of the (sub)dimensions

\begin{tabular}{|c|c|c|c|c|c|c|}
\hline (Sub)dimensions & Mean & $\begin{array}{c}\text { Std. } \\
\text { Deviation }\end{array}$ & Minimum & Maximum & MV & $\mathrm{N}$ \\
\hline IQ_completeness & 4,29 & 0,65 & 1,00 & 5,00 & $34,7 \%$ & 1041 \\
\hline IQ_sufficiency & 3,83 & 0,91 & 1,00 & 5,00 & $36,0 \%$ & 1019 \\
\hline IQ_accuracy & 3,98 & 0,73 & 1,00 & 5,00 & $38,7 \%$ & 977 \\
\hline IQ & 4,04 & 0,61 & 1,33 & 5,00 & $39,5 \%$ & 963 \\
\hline SQ_ease of learning & 4,01 & 0,90 & 1,00 & 5,00 & $38,8 \%$ & 975 \\
\hline SQ_ease of use & 3,90 & 0,96 & 1,00 & 5,00 & $38,8 \%$ & 975 \\
\hline SQ_performance & 3,45 & 1,06 & 1,00 & 5,00 & $39,8 \%$ & 959 \\
\hline SQ_security & 4,12 & 0,68 & 1,00 & 5,00 & $42,3 \%$ & 919 \\
\hline SQ & 3,87 & 0,68 & 1,50 & 5,00 & $43,9 \%$ & 893 \\
\hline SV_reliablity & 3,72 & 0,78 & 1,00 & 5,00 & $58,5 \%$ & 661 \\
\hline SV_empathy & 3,72 & 0,85 & 1,00 & 5,00 & $52,5 \%$ & 757 \\
\hline SV_follow-up service & 2,78 & 1,23 & 1,00 & 5,00 & $49,5 \%$ & 804 \\
\hline SV & 3,47 & 0,75 & 1,00 & 5,00 & $64,3 \%$ & 569 \\
\hline $\mathrm{ITU}^{2}$ & 0,52 & 0,50 & 0,00 & 1,00 & 0 & 1593 \\
\hline US_Personal satisfaction & 6,78 & 1,54 & 0,00 & 10,00 & $39,4 \%$ & 965 \\
\hline US_Word of mouth commmication & 6,93 & 1,96 & 0,00 & 10,00 & $34,7 \%$ & 1040 \\
\hline US (PS + WoMC) & 6,91 & 1,60 & 0,00 & 10,00 & $39,5 \%$ & 963 \\
\hline NB_Job & 3,45 & 1,00 & 1,00 & 5,00 & $37,4 \%$ & 998 \\
\hline NB_Task & 3,14 & 1,05 & 1,00 & 5,00 & $36,4 \%$ & 1013 \\
\hline NB_Organisation & 3,93 & 0,96 & 1,00 & 5,00 & $35,6 \%$ & 1026 \\
\hline NB & 3,51 & 0,87 & 1,00 & 5,00 & $38,5 \%$ & 979 \\
\hline
\end{tabular}

${ }^{1}$ This dimension is not displayed on a 5-point Likert scale but as a dummy variable, the US subdimensions are measured on a 10-point scale

Note: ITU= intention to use, IQ= information quality, $\mathrm{SV}=$ service quality, $\mathrm{SQ}=$ system quality, $\mathrm{US}=$ user satisfaction,

$\mathrm{NB}=$ net benefits. 
Table 4 Principal component analysis of ten quality subdimensions

\begin{tabular}{|l|c|c|c|}
\hline & 1 & 2 & 3 \\
\hline *IQ_completeness & 0,029 & 0,044 & 0,800 \\
\hline *IQ_sufficiency & 0,221 & 0,214 & 0,770 \\
\hline *IQ_accuracy & 0,337 & 0,218 & 0,699 \\
\hline *SQ_ease of leaming & 0,609 & 0,326 & 0,364 \\
\hline *SQ_ease of use & 0,683 & 0,334 & 0,362 \\
\hline *SQ_performance & 0,753 & 0,083 & 0,017 \\
\hline *SQ_security & 0,727 & $-0,027$ & 0,168 \\
\hline *SV_reliablity & 0,35 & 0,762 & 0,104 \\
\hline *SV_empathy & 0,246 & 0,815 & 0,144 \\
\hline *SV_follow-up service & $-0,141$ & 0,732 & 0,171 \\
\hline Eigenvalue & 4,1 & 1,3 & 1,1 \\
\hline Cumulative explained variance & 41,3 & 12,5 & 10,9 \\
\hline$N$ & & 479 & \\
\hline
\end{tabular}

Note: $\mathrm{IQ}=$ information quality, $\mathrm{SV}=$ service quality, $\mathrm{SQ}=$ system quality

Table 5 Degree support for hypotheses

\begin{tabular}{|c|c|c|c|c|c|}
\hline \multirow{2}{*}{$\begin{array}{c}\text { Hypo- } \\
\text { thesis }\end{array}$} & \multicolumn{2}{|c|}{ Variables } & \multicolumn{4}{|c|}{} \\
\cline { 2 - 6 } & I.V. & D.V. & $\beta$ & Sig. & N \\
\hline H2 & IQ & US & 0,152 & $<0,001$ & 963 \\
\hline H4 & SQ & US & 0,320 & $<0,001$ & 893 \\
\hline H6 & SV & US & 0,230 & $<0,001$ & 569 \\
\hline H7 & U & US & 0,099 & $<0,005$ & 963 \\
\hline H9 & U & NB & 0,031 & 0,330 & 979 \\
\hline H10 & US & NB & 0,574 & $<0,001$ & 965 \\
\hline H12 & NB & US & 0,642 & $<0,001$ & 900 \\
\hline Hypoth & Variables & \multicolumn{4}{|c|}{} \\
\cline { 2 - 6 } esis & I.V. & D.V. & Nagelkerke R & Sig. & N \\
\hline H1 & IQ & ITU & 0,086 & $<0,001$ & 963 \\
\hline H3 & SQ & ITU & 0,046 & $<0,001$ & 893 \\
\hline H5 & SV & ITU & 0,055 & $<0,001$ & 1024 \\
\hline H8 & US & ITU & 0,256 & $<0,001$ & 963 \\
\hline H11 & NB & ITU & 0,262 & $<0,001$ & 979 \\
\hline
\end{tabular}


Table 6 Regression coefficients

Coefficients $^{\mathrm{a}}$

\begin{tabular}{|c|c|c|c|c|c|c|c|}
\hline \multirow[t]{2}{*}{ Model } & \multicolumn{2}{|c|}{ Unstandardised Coefficients } & \multirow{2}{*}{$\begin{array}{c}\begin{array}{c}\text { Standardised } \\
\text { Coefficients }\end{array} \\
\text { Beta }\end{array}$} & \multirow[t]{2}{*}{$\mathrm{t}$} & \multirow[t]{2}{*}{ Sig. } & \multicolumn{2}{|c|}{ Collinearity Statistics } \\
\hline & $\mathrm{B}$ & Std. Error & & & & Tolerance & VIF \\
\hline (Constant) &, 811 & ,229 & & 3,544 & 000 & & \\
\hline *IQ &, 103 & 059 & 079 & 1,758 & 080 & ,703 & 1,421 \\
\hline$* \mathrm{SQ}$ &,- 016 &, 055 &,- 014 &,- 287 & ,774 & 627 & 1,596 \\
\hline$* \mathrm{SV}$ &, 157 & 047 &, 145 & 3,333 & 001 & ,743 & 1,345 \\
\hline (No) ITU* & ,205 & , 113 &, 076 & 1,813 & ,071 & ,804 & 1,244 \\
\hline $\begin{array}{l}\text { US (2 subdim.) } \\
\text { * US }\end{array}$ & ,256 & 027 & , 490 & 9,416 & ,000 &, 522 & 1,916 \\
\hline
\end{tabular}

a. Dependent Variable: *Net benefits (aggregated)* 